\title{
Desafios do eneontro entre migrantes e comunidades cristãs: reflexões sobre situạ̄ões de vulnerabilidade
}

\section{Challenges of the encounter between migrants and christian communities: Reflections on situa- tions of vulnerability}

\section{Carmem Lussi*}

Recebido: 10/10/2017. Aprovado: 30/11/2017.

Resumo: A intensificação dos fluxos de migrações internacionais, em muitas Igrejas locais, vem acompanhada de esforços para promover e sustentar ações de assistência em situações de vulnerabilidade humana, social e jurídica. A categoria da vulnerabilidade entendida como possibilidade de ser ferido (ou de ferir) ajuda a interpretar os desafios que os sujeitos em situação de mobilidade humana atravessam. As comunidades cristãs de chegada dos fluxos igualmente enfrentam desafios nos processos relativos à presença de migrantes e à reinvenção das relações e das práticas de vida cristã, interpeladas pelo fenômeno da mobilidade humana. $O$ artigo propõe reflexões em perspectiva missionária.

Palavras-Chave: Protagonismo. Vulnerabilidade. Eclesiologia. Migrantes.

Abstract: The intensification of international migration flows in many local Churches is accompanied by efforts to promote and sustain actions of assistance to people in situations of human, social and legal vulnerability. The category of vulnerability includes the possibility of being hurt (or hurting) and helps to interpret the challenges faced by individuals in a situation of human mobility. The Christian communities of arrival of the flows also have to handle with challenges in the processes related to the presence of migrants and the reinvention of the relations and practices of Christian life, called by the phenomenon of human mobility. The article proposes reflections in a missionary perspective.

Keywords: Protagonism. Vulnerability. Ecclesiology. Migrants.

* Doutora em Teologia (Pontifícia Universidade Católica do Rio de Janeiro - PUC-Rio, 2013). Mestre em Missiologia (Pontificia Università Urbaniana, Roma, 2002). Assessora do CSEM - Centro Scalabriniano de Estudos Migratórios. Membro do NIEM - Núcleo Interdisciplinar de Estudos Migratórios do Rio de Janeiro.

E-mail: carmem.lussi@gmail.com 


\section{Introdução}

A complexa relação entre experiência religiosa e espiritual dos migrantes e diferentes formas de fragilidade institucional das realidades eclesiais locais onde acontecem os percursos migratórios interpela a reflexão teológica e pastoral ${ }^{1}$. Tento explorar, neste artigo, a relação entre o protagonismo migratório dos sujeitos em situação de mobilidade por migração, refúgio ou retorno e a vulnerabilidade eclesial, sugerindo chaves interpretativas para a complexidade dos contextos eclesiais com incidência de fluxos de mobilidade humana. Após ilustrar os dois polos principais da problematicidade, sobre a qual aproximo o foco neste texto, aponto alguns desafios de uma abordagem a essas temáticas, na perspectiva da missionariedade.

\section{Protagonismo dos atores em situação de mobilidade humana}

As graves violações de direitos humanos que são registradas diariamente nos contextos onde há mobilidade humana, os repetidos registros de mortes nas travessias perigosas e as ameaças para a vida e a dignidade de migrantes e refugiados, especialmente nos países onde há políticas anti-imigração, fortalecidas por discursos e práticas xenófobas e criminalização dos sujeitos dos fluxos de migrações internacionais e de refúgio, reforçam uma visão vitimizante dos migrantes e refugiados. Mesmo assim, cresce a consciência entre os atores dos fluxos, estudiosos e lideranças que atuam na temática, que a mobilidade humana, mesmo quando incide em modo determinante marcando situações de vulnerabilidade sobre os sujeitos dos percursos migratórios, é uma oportunidade para quem migra, para seus respectivos contextos, para a sociedade em geral e, com suas especificidades, também para as igrejas. E, enquanto

1 Tratei este tema mais amplamente no livro que publicou os resultados de minha pesquisa de doutorado: LUSSI, Carmem. Migrações e alteridade na comunidade cristã. Ensaio de teologia da mobilidade humana. Brasília: CSEM, 2015. Mais detalhes sobre a metodologia utilizada encontram-se em minha tese doutoral "Circularidade entre migrações e fé. Reflexões sobre a alteridade na Igreja de comunhão", 2013. Disponível em: $<$ http://www2.dbd.puc-rio.br/pergamum/tesesabertas/0821110_2013_completo.pdf>e no artigo LUSSI, Carmem. "A Grounded Theory da circularidade entre migrações e fé. Uma proposta metodológica para pesquisa de campo em teologia" in SOTER (Org.). Anais do Congresso da SOTER 25․ Congresso Internacional da SOTER Sociedade de Teologia e Ciências da Religião. Belo Horizonte: SOTER; 2012, pp. 1113-1138. Disponível em: <http://www.soter.org.br/biblioteca/anais_congresso_soter_2012.pdf>. 
tal, a mobilidade humana tem um potencial transformador sobre as realidades que são tocadas pelos fluxos populacionais.

Em particular, fala-se de protagonismo, referido à capacidade dos sujeitos, individuais e coletivos dos fluxos de mobilidade humana, de exercer uma subjetividade ativa e responsável, incidindo em seus projetos pessoais, assim como nas relações que vivem, junto às instituições com as quais interagem e na sociedade em geral, não menos que na Igreja. Protagonista é aquela pessoa que toma a iniciativa, que age, que é por excelência ativa e não passiva perante as situações, que exerce sua liberdade e singularidade tomando decisões e interagindo propositivamente com atores e contextos.

A palavra protagonismo ${ }^{2}$ reúne duas raízes gregas. Prótos, que significa primeiro ou primitivo e agon $^{3}$, que significa luta ou disputa. $\mathrm{O}$ termo agon é raiz da palavra 'agonismo' e indica o empenho do atleta durante o desenvolvimento de uma disputa esportiva, assim como a tensão dos desafios e do confronto. O protagonismo é de cada sujeito, não é algo que se possa receber de outros nem um processo ou efeito que acontece sem o envolvimento efetivo da pessoa ou do grupo interessado. O termo indica ainda o esforço e a condição pela qual sujeitos em situação de mobilidade se movimentam e se relacionam com contextos marcados por desafios e lutas, muitas vezes se debatendo em combates até ímpares, em sua jornada migratória, seja no contexto eclesial que naquele social ou político.

O reconhecimento de um protagonismo por parte dos sujeitos em mobilidade favorece uma abordagem da temática migratória que vai além da necessidade de sublinhar os riscos e ameaças que migrantes e refugiados enfrentam, para identificar as potencialidades que pessoas e processos trazem consigo no acontecer migratório, na comunidade cristã onde os fluxos acontecem, não menos que na sociedade em geral.

Saber identificar onde e como pode ser favorecido ou exercitado um protagonismo ativo de pessoas e grupos em mobilidade é prevenir a exclusão e melhorar a capacidade de incidência, junto com a quali-

2 Cf. o verbete Protagonismo no Dicionário sobre migrações internacionais, que está em processo de publicação, de autoria dos organizadores Leonardo Cavalcanti, Tânia Tonhati e Tuíla Botega, pela Editora Universidade de Brasília.

3 MERLOTTI, Dominique. Radici greche. Capire meglio la propria lingua. Jesolo Lido (VE), 2010. Apud Jean Bouffartique, Anne-Marie Delrieu. Tresorts des racines grecques. Paris: Belin, 2002. 
dade de vida de migrantes e refugiados, prevenindo vulnerabilidades, fortalecendo a resiliência e ampliando a coesão social e o sucesso dos processos migratórios. Todavia, cabe ressaltar que as potencialidades podem ser neutralizadas por situações de vulnerabilidade, portanto, não se trata de contrapor promessa a ameaça, mas manter a complexidade do fenômeno, sem simplificações nem reducionismos, para que as estratégias de desenvolvimento do projeto migratório sejam capazes de otimizar as oportunidades.

O exercício do protagonismo em contexto migratório comporta a superação das assimetrias que enfraquecem e até distorcem o encontro entre pessoas e grupos humanos provenientes, originariamente, de culturas, idiomas, mentalidades, histórias e religiões diferentes. Portes ${ }^{4}$ sugere que existe um protagonismo, sutil e transversal, intrínseco aos processos migratórios pelo simples fato que, emigrando, a pessoa realiza um ato existencial e político, o qual, por sua vez, interpela os governos de origem, que, antes da emigração, não percebem que muitas faixas da população são compostas por potenciais emigrantes. E desafia os governos de trânsito e de destino, que apesar das políticas e das leis restritivas, não conseguem estancar os fluxos migratórios. A sugestão de Alejandro Portes abre perspectivas também para a interpretação eclesial do protagonismo migratório. O peso internacional do ato de migrar faz da população em movimento, antes invisíveis e irrelevantes no lugar de origem, pessoas que tem voz e peso em nível internacional. Igualmente, a relevância dos fluxos migratórios para a comunidade cristã é uma provocação, pois a presença de sujeitos e grupos em situação de mobilidade interpela por causa da diversidade que traz para os contextos locais e, muitas vezes, pela inércia da Igreja local que fica exposta por incapacidade de perceber, interpretar e comunicar com os sujeitos novos que a desafiam, como é o caso de migrantes, itinerantes e pessoas em busca de proteção internacional.

A incidência da experiência migratória é determinante sobre a qualidade e a configuração da experiência eclesial de migrantes e refugiados e provoca transformações profundas nas formas do crer e da vivência religiosa, muitas vezes prescindindo da pertença ou participação a qualquer comunidade de fé. Isso favorece uma distância ou ausência

$4 \quad$ PORTES, Alejandro. "Convergencias teóricas e evidencias empíricas en el estudio del transnacionalismo de los inmigrantes" in Migración y desarrollo, I semestre, 2005, pp. 2-19. 
da Igreja na saga migratória ou dos crentes migrantes na vida da Igreja. Tal ausência pode ser real, como pode indicar uma percepção de ausência, devido às diferenças no quadro de referência das duas partes - os sujeitos em situação de mobilidade e a Igreja local de imigração - sobre organização, práticas e visão da vivência da fé e das relações no âmbito eclesial. As ausências se referem à falta de interlocução, não à falta de existência da Igreja e de suas estruturas, práticas e atores no território nem, necessariamente, à falta de fé e de vida comunitária na vivência cristã dos migrantes.

A falta de interlocução indica falta de relações e revela aspectos da vulnerabilidade eclesial que se transformam em situações de fragilidade também para as pessoas em mobilidade, porque no encontro entre sujeitos migrantes ou refugiados e Igreja local, espera-se que seja a comunidade cristã e seus autores in loco os que exerçam a parte principal do movimento de saída para que o encontro aconteça.

Nas falas dos migrantes, muitos testemunham um caminho de fé favorecido pela experiência migratória, referindo sobre motivos de crise em sua vivência comunitária. Entre as razões pelas quais optam pelo não pertencimento a uma comunidade cristã, além da inviabilidade de participar por motivos de horários de trabalho, dois motivos são particularmente desafiadores para a missionariedade eclesial: por um lado, a extrema distância de mentalidade e jeito de ser cristãos entre a realidade que encontraram no contexto de chegada de seu percurso migratório e a experiência pessoal de vivência cristã que se transformou e libertou durante o projeto migratório; e, por outro, a qualidade das relações e das atividades, que não envolvem a vida, não desvelam significados existenciais, nem alimentam efetivamente a fés.

A experiência migratória interroga o modelo de comunidade cristã e a qualidade da vivência comunitária, pois a prova do movimento de deslocamento geográfico e cultural vale como filtro seletivo das prioridades que os sujeitos internalizam em sua visão e experiência de vida cristã. $O$ encontro de sujeitos provindos de outras Igrejas locais em novos contextos de imigração com atores individuais ou coletivos da nova realidade eclesial comporta sempre um esforço para ambas as partes, pois além das fragilidades e resistências de ambos os lados, as diferenças questionam os modelos e exigem a invenção de novas estratégias de inter-relação e de vivência. A qualidade de uma comunidade

5 LUSSI, Carmem. Migrações e. p. 232. 
não está tanto nas funções que as pessoas exercem para construí-la ou para consolidá-la e para fazer com que a experiência comunitária seja autêntica e produza frutos, mas especialmente no poder e na habilidade que a mesma comunidade tem de fazer as pessoas renascerem e crescerem, amadurecerem e tornarem-se quem são chamadas a ser, não sem as relações que fazem os processos acontecerem: "nós nos tornamos quem somos tentando e possivelmente realizando o nascimento biológico, aquele psicológico, social e espiritual até a plenitude do amor, passando pela hospitalidade maiêtica de diferentes comunidades'(MANCINI, 2004, p. 135)'.

O protagonismo dos sujeitos migrantes, que se configura e consolida por causa da fé, no âmbito de experiências de mobilidade humana, se concretiza, normalmente, como um dos aspectos do próprio processo de reinvenção das formas do crer e do agir, que acontece dentro da comunidade cristã ou prescindindo desta. Participar, com possibilidade de incidir nos processos, nas relações e nas escolhas é protagonismo que migrantes e refugiados são capazes, à condição de ter acesso à comunidade, para poder colaborar, em funções religiosas ou sociais, culturais ou simplesmente interpessoais.

É a condição cristã que pede, exige e determina o protagonismo, em virtude do batismo, e não da familiaridade com o estilo e a tradição local; porém a falta de familiaridade com idioma, costumes e amizades num determinado contexto pode ser fator de exclusão de novos membros, especialmente quando são migrantes internacionais em que os elementos de alteridade podem ser muito fortes.

\section{Protagonismo e vulnerabilidade eclesial}

A reflexão sobre a busca por reconhecimento do protagonismo migrante em contexto eclesial aponta para uma visão da realidade eclesial referida à sua relevância para a vivência cristã como sendo vulnerável, não tanto no sentido de possibilidade de ser ferida, quanto no sentido de fragilidade e incoerências em sua identidade e por sua capacidade de ferir no âmbito da relação, por não saber prescindir de, nem reconhecer suas situações, expressões e atores marcados por vulnerabilidades.

A vulnerabilidade eclesial não é entendida em contraposição ao protagonismo da Igreja e ao dos sujeitos em mobilidade, mas como fra-

$6 \quad$ Idem, p. 234. 
gilidade identitária da Igreja que, por insegurança e eventual fragilidade nos laços que a fazem atingir das fontes da Escritura e da espiritualidade encarnada, afeta a qualidade da vida e a credibilidade de seus atores, membros novos e velhos. A riqueza da diversidade de tradições eclesiais locais pode esconder contraposições quando as diferenças se encontram através das migrações revelando formas de rigidez e esquizofrenia, em que práticas e crenças se sobrepõem à linfa fresca da Palavra e da vivência plural dos cotidianos criativos que o Espírito suscita nas comunidades. A chegada de pessoas com fé de outras terras, pelo simples fato de trazerem prioridades, modos de celebrar e vivências alternativas às que as comunidades de acolhida adotam, pode gerar conflitos e contraposições, que empobrecem e desagregam, multiplicando vulnerabilidades, ao invés de fecundar pelo poder transformador de Pentecostes.

Esses tipos de empasses se apresentam como perda de presença dos cristãos e de suas comunidades no cenário social e cultural e intensifica os processos de distanciamento dos cristãos em relação às formas históricas do crer que a tradição consolidou, para dar lugar à reinvenção da fé, que é própria do fato migratório, que acolhida e acompanhada pela Igreja se torna motivo e ocasião de revigoramento e apertura missionária para todos os atores; mas que abandonada a si mesma, se torna processo que simplesmente favorece a privatização do religioso e até mesmo a indiferença religiosa ${ }^{7}$, onde as vulnerabilidades que a mobilidade humana traz consigo se acumulam com às da fragilidade de relações e de testemunho da vivência cristã do contexto de chegada dos fluxos.

Tais situações exprimem uma perda de visibilidade e de credibilidade da Igreja e, mesmo sem generalizar, de certa forma pode-se afirmar que é uma perda que de fato enfraquece a capacidade de incidência das instituições religiosas nos percursos existenciais dos sujeitos, especialmente dos que, a partir de um nomadismo geográfico, social e cultural, são capazes de assumir um nomadismo espiritual que é autêntica busca pelos significados que só a fé sabe forjar, desvendar e/ou atribuir.

Importantes movimentos de expansão do cristianismo se deram, historicamente, através do esforço das Igrejas de acompanhar seus fiéis que emigravam mundo afora. Tais Igrejas, hoje, implantadas, têm dificuldade de se desinstalar provocadas pelos movimentos existenciais e populacionais de seus membros, velhos e novos, apesar do incisivo apelo

7 Cf. COSENTINO FRANCESCO. "II nuovo volto della non credenza". Prospettive teologiche e sfide pastorali. Euntes Docete v. 1, n. 70, 2017, pp. 11-27. 
de papa Francisco por uma 'Igreja em saída'. E essa estabilidade amorfa se transforma em esconderijo de vivências medíocres e de aparências, que torna muitos atores impermeáveis aos novos desafios da dinamicidade da fé que vêm da história ou da Palavra iluminadora que permeia e re-significa os fatos da vida dos crentes e de suas comunidades.

Às crises a que a migração submete os sujeitos que ousam deixar suas terras em busca de algo melhor no exterior, correspondem crises eclesiais, de identidade, de motivação, de configuração histórica das práticas e das linguagens, de relações. Sujeitos corajosos ou flexíveis, que se deixam transformar enquanto migram, já não se adaptam à rigidez das instituições religiosas que ainda pretendem determinar e configurar as formas do crer das pessoas, que por sua vez, querem incidir nos âmbitos religiosos, como nos demais em que vivem e convivem. E como a rigidez das comunidades é feita de sujeitos concretos, o potencial transformador da experiência migratória é uma oportunidade para as comunidades, à condição que a acolhida abra a porta para relações envolventes, que não sem crises, podem ser fermento na massa.

As religiões contam com os indivíduos para realizar sua missão em contextos que as pessoas ocupam por razões de vida e trabalho, no mundo. Entretanto, migrantes e refugiados, reconhecidamente, dificilmente poder valer-se das instituições religiosas para alcançar seus fins e superar os obstáculos e as fragilidades que enfrentam em suas trajetórias, por isso, também dificilmente podem adotar para si a perspectiva de ser a Igreja no mundo, se não podem contar com a Igreja em sua porção de mundo, que é sua trajetória de mobilidade. A compreensão dessa contradição é um dos desafios promissores da chegada de 'estrangeiros' nas realidades eclesiais locais.

À tradicional força com a qual as religiões tradicionalmente se impunham sobre os indivíduos ditando regras de vida, normas de comportamento e padrões de convivência corresponde, sempre mais, uma individualização da religião pela qual os sujeitos, mesmo sem rejeitar explicitamente os padrões tradicionais, tomam distância reinventando e adotando regras e estilos de vida, de práticas sociais e religiosas e até normas de convivência que ignoram e, portanto, prescindem das instituições religiosas. Este fenômeno difuso tem, nos sujeitos e nos grupos em mobilidade, atores particularmente incisivos, pela liberdade que estes têm de atuar em contextos novos, nos quais a pressão da tradição lhes é estranha ou pouco relevante. 
Acreditando, com Georg Simmel, que a religiosidade é a "capacidade humana, histórica e culturalmente determinada, de elaborar sentidos para o conjunto da existência" ${ }^{\prime}$, pode-se considerar que, de fato, experiência migratória e experiência religiosa possam se fecundar reciprocamente pela profundidade e pela relevância que revestem, antropologicamente, em todos os tempos.

\section{Uma específica vulnerabilidade eclesial: a fé que dispensa a Igreja}

A interpretação do desafio missiológico que a mobilidade humana representa em certos contextos eclesiais a partir da categoria da vulnerabilidade eclesial inclui um aspecto bem preciso, que é aquela vulnerabilidade da instituição religiosa que é considerada dispensável e até obstáculo para a vivência da fé, o que emerge com particular relevância quando é afirmado e argumentado, não por ateus nem por cristãos com feridas e tensões históricas com/contra algum ator ou alguma instituição eclesial, mas por sujeitos crentes, que se consideram sinceramente peregrinos da fé, que buscam a vivência cristã com verdadeira sede de Deus e desejosos de "viver intensamente a comunhão fraterna e a integração entre fé e história a partir da realidade e da vida concreta".

A lógica da encarnação e do anúncio do Deus cristão como Deus-conosco é uma compreensão da vivência cristã que os cristãos migrantes se apropriam com propriedade, favorecidos pela distância geográfica e simbólica que a migração faz acontecer. Então, a reinvenção de uma forma 'outra' do crer, adequada ao novo momento existencial e histórico que a mobilidade humana configura para seus sujeitos nem sempre significa abandono da fé, mas pode significar estranheza para com as formas institucionalizadas da prática religiosa. As posturas rígidas, engessadas, focadas em práticas e gestos arcaicos, com moralismos sem argumentação bíblica e discursos que não nutrem nem ajudam a interpretar significados de fé das vivências por parte das Igrejas, favorecem outras posturas, de migrantes e refugiados que podem, simplesmente, adotar para si visões personalizadas na relação com o Deus de Jesus, do qual ouviram falar

$8 \quad$ RIBEIRO, Jorge Claudio. "Educar na religiosidade: pesquisa e experimento com universitários" em Revista Instrumento - Revista de Estudo e Pesquisa em Educação, v. 11, n. 2, 2009, pp. 49-58, aqui p. 49.

9 CNBB. As comunidades eclesiais de base na Igreja do Brasil, 1982, n. 51. 
e com o qual nutrem um diálogo confiante. O registro de tensões entre migrantes provenientes de outras Igrejas locais em comunidades cristãs de chegada é comum, mesmo sendo aparentemente algo relacionado com superficiais diferenças de prioridades e de procedimentos. Na realidade, revelam divergências de visão de Deus e de Igreja e, sobretudo, indicam um distanciamento entre a vivência crente dos homens e das mulheres migrantes e a capacidade das lideranças eclesiais de entrar em relação de fé e amor com tais experiência de fé e de vida.

O que é uma pobreza trágica, que é quanto maior quanto mais expressiva for a dificuldade de escuta e diálogo entre figuras que se sentem ou são identificadas como representantes eclesiais e os e as 'peregrinos' nas vias da mobilidade humana e da experiência do discipulado que precisa reconfigurar-se, na nova Igreja local.

A distância existencial entre os dois lados do cenário constitui-se em vulnerabilidade, seja a que se desdobra como fragilidade que a que fere, gerando impasse e dificultando o desenrolar dos processos de crescimento intrínseco a cada um dos atores. Tal crise favorece a fé de consumo, que serve enquanto fornece o que o viandante precisa e até que o necessite, para ser dispensada como irrelevante, quando o cotidiano volta à normalidade ou exige algo mais.

A fé que dispensa a Igreja não é um traço específico que se possa atribuir aos sujeitos dos fluxos de mobilidade humana. É uma atitude interior de confiança que se fortalece nas vias das migrações exatamente por causa da mobilidade e dos sofrimentos que a determinam, enquanto é recorrente que os sujeitos registrem um inegável distanciamento e estranhamento da instituição eclesial. Tal vivência de uma fé personalizada à prova da ausência eclesial e até mesmo de alguma forma de comunidade, muitas vezes, se configura como uma forma do crer com aspectos fortes de uma relação pessoal com o sagrado, nos termos e com as características do seguimento ao Deus de Jesus Cristo, como é apresentado nos Evangelhos. Interrogados sobre a relação entre experiência da fé e experiência migratória, não é raro ouvir de migrantes e refugiados, mesmo sem tradição cristã, a expressão de certezas referidas sobre uma presença divina que os conduziu, protegeu, salvou nas trajetórias da mobilidade vivida e que se revela, constantemente presente e interlocutor em suas jornadas existenciais. Paradoxalmente, a ausência da Igreja ou de sua atuação missionária e de cuidado nos percursos migratórios, muitas vezes, se revela como fator de purificação de uma religiosida- 
de herdada, onde a práticas pouco enraizadas na vida dos crentes se deteriora. Isso não exclui que, ao meso tempo, possa se fortalecer, por outros canais, uma fé relacional que permeia as demais relações que as pessoas sustentam, com os bens, com suas histórias e com as pessoas de seus contextos familiares e sociais. E tal fé se afirma como ética, como perfil que determina qualidade e estilo de valores, de vida e de metas a alcançar, para si e para os seus.

\section{Desafios emergentes em perspectiva missionária}

Ao invés de elementos conclusivos, aponto ao final desse artigo alguns desafios missionários que a abordagem missiológica à temática migratória com foco na temática abordada nesse testo revela em modo particular.

O primeiro e principal desafio é o reconhecimento da mobilidade humana, por parte da comunidade cristã como kairós, uma oportunidade única e estimulante para voltar à Palavra de Deus, pois se a reprodução de práticas religiosas e estilos consolidados no tempo de vivência comunitária, de catequese e até celebração da fé, que transmitem e realizam por repetição aprendida desde sempre vale entre os autóctones, com migrantes normalmente apresenta dificuldade. Os migrantes tendem a querer reproduzir as práticas das Igrejas de origem, se ainda são importantes, dificilmente abraçam de imediato práticas novas, se não decorrem de caminho de fé e de vivência comunitária. Pessoas vindas de outras Igrejas locais podem não conhecer nem reconhecer o valor evangélico ou cristão de muitas práticas e falas.

É preciso voltar à escuta da Palavra, seja para reinventar vida cristã e comunidade entre cristãos de velha data, seja para não trair a dimensão missionária da vocação cristã e o ser Igreja em saída para encontrar e acolher seja cristão provindos de outras terras, seja quem nunca ouviu o anúncio ou ainda não teve oportunidade de contemplar e interpretar a presença de Deus em sua vida e em seu percurso migratório. Pelo fato que "a Palavra cria a comunidade dos crentes e, ao mesmo tempo, a Igreja é criatura da Palavra, a possibilidade de existência da Igreja na história humana acontece somente a partir dessa correlação: da escuta da mensagem da salvação realizada em Cristo, veio à existência a Igreja 
enquanto comunidade dos que creem e aceitam o kerigma cristão"10, como foi paradigmaticamente revelado em Pentecostes, segundo a narrativa de At 2 .

Outro desafio primordial é a capacidade de apostar na liberdade missionária de Deus, que não depende nem se deixa condicionar pela imprescindível, e por vezes, lenta e até negligente atuação da comunidade para alcançar e para interagir com os sujeitos que são chamados, pela graça de Deus e pelas trajetórias existenciais e migratórias, ao evento da fé e do seguimento de Jesus Cristo. A especificidade do Evangelho do Reino é que existe um agir comunicativo de Deus, como explica Dianich, que é portador da koinonia e que precede o ato da comunicação da fé entre os crentes, que é o agir comunicativo de Deus na sua autorrevelação a cada ser humano. Esta comunicação divina acontece na contingência das realidades migratórias e autóctones concretas e historicamente diferentes, constituindo a Igreja "como sujeito histórico, empiricamente verificável, somente no momento em que uma pessoa humana comunica a outra sua fé"11. E os discípulos missionários se reconhecem, nesse dinamismo, como atores principais na execução do enredo durante o qual as comunidades locais resistem à tentação de sedentarismo e fossilização através da humilde e feliz leitura do que Deus faz acontecer e de como convoca os crentes a reinventar modalidades para viver sua fé nos fatos, nos encontros e nos desencontros novos que a vida e a história fazem acontecer, superando assim as próprias vulnerabilidades, ajudando a superar as da comunidade e prevenindo as ameaças para o abandono da fé e os riscos para a vida e os direitos de outros e outras, inclusive migrantes e refugiados. Em tais comunidades, os novos membros descobrem que tem o 'direito a ser diferentes' sem o medo de sofrer a discriminação e um trato desigual.

Um terceiro desafio, também relacionado com a liberdade missionária de Deus, é a liberdade primordial dos crentes, inclusive dos que passam por trajetórias de deslocamentos populacionais e podem não ter interesse, disponibilidade ou abertura de mente e de coração para a interação com a comunidade cristã nos locais de destino, de

10 MAZZOLINI, Sandra. "Chiesa comunione e diálogo. Una correlazione essenziale" in Euntes Docete, v. 63, n. 3, 2010, pp. 149-171, aqui p. 159.

11 DIANICH, Severino. "Questioni di metodologia in ecclesiologia" in BARRUFFO, Antonio (ed.). Sui problemi del metodo in ecclesiologia. In dialogo con Severino Dianich. Cinisello: San Paolo, 2003, p. 49. 
fazer percursos alternativos. E podem ainda acolher Jesus Cristo e sua mensagem, mantendo e até mostrando reservas e resistências às modalidades do crer que a comunidade local adota em sua vivência cristã, sendo por sua vez cristãos de 'outro jeito'. O que não dispensa uma comunidade local de questionar-se sobre a qualidade de seu testemunho e os significados para sua fé, estimulados pelo distanciamento proposital de cristãos e não cristãos provindos de outras terras. Este também é um desafio, porque a estrutura dialógica da fé, nos contextos de antiga evangelização onde a adesão pelo batismo precede a maturidade humana, pode ser irreconhecível e a interação com cristãos diferentes e não cristãos pode ser interpelador e enriquecer para todos os atores da interlocução.

Enfim, um quarto desafio missionário está na visão de Igreja e de participação do povo de Deus que se adota nas falas e nos gestos, que incide em modo imprescindível na perspectiva da interação, ou não, entre sujeitos em situação de mobilidade e comunidade cristã local. O protagonismo é também um termo que ajuda a pensar as subjetividades na comunidade cristã autóctone, não só seus membros imigrantes. O termo protagonismo, referido aos cristãos, ganhou força na Conferência de Santo Domingo, em 1992: "Que todos os leigos sejam protagonistas da Nova Evangelização, da promoção humana e da cultura cristã" (n. 97). Já no Documento de Aparecida o protagonismo dos cristãos aparece como participação na Missão de Cristo confiada à Igreja e como corresponsabilidade na construção da comunidade cristã e da Igreja, como um todo.

Leigos e Leigas devem participar, como sujeitos, com vez e voz, na elaboração dos programas pastorais, nos centros de discussão e decisão nas Igrejas Particulares. Referindo-se ao projeto pastoral da Diocese, o Documento de Aparecida afirma: "Os leigos devem participar do discernimento, da tomada de decisões, do planejamento e da execução." (n. 371). Não podem, portanto, verem reduzida a sua participação apenas ao momento de encaminhar e realizar os programas, mas sentirem-se participantes desde o início, por força da sua condição de cristão batizado, habilitado pelos sacramentos do Batismo e da Confirmação, a participar plenamente da vida da Igreja (DAp 283) ${ }^{12}$.

12 KENAN, Milton Júnior. "Leigos e leigas no protagonismo da evangelização", s/d. Disponível em: <http://www.xaverianos.org.br/leigos-e-leigas-no-protagonismo-da-evangelizacao/>. 
É o que espelha a experiência das CEBs, que "favoreceu a gênese de um novo rosto de Igreja, caracterizado pelos traços da comunhão, compromisso e participação e pontuado pela dinâmica do seguimento de Jesus Cristo"13.

Com Ana Maria Tepedino, acredito que também para os migrantes e refugiados, estrangeiros com tradição cristã ou totalmente estranhos e até adversos a esta, cabe o reconhecimento de uma alteridade, que pode abrir caminhos a novos estilos e nova qualidade nas relações, para que não sejam "entendidos de forma anônima e como objeto de solidariedade" e passem a ser, cada vez com mais força, sujeitos "de uma caminhada eclesial e social em defesa da vida diminuída", pra que possam emergir, desde dentro de suas reais situações de vida e de fé, rostos de gente que se tornam visíveis e que apontam para a necessidade "de ir além de análises sócio-políticas-econômicas, pois, a cultura também deveria ser levada em conta. Os empobrecidos culturais começam a lutar para fazer escutar suas vozes, e também se tornarem protagonistas"14.

\section{À guisa de conclusão}

As violações de direitos humanos e as situações de vulnerabilidade relacionadas com o fato migratório têm favorecido, no contexto eclesial, uma abordagem 'pauperista' e assistencialista aos sujeitos em situação de mobilidade. Se por um lado este tipo de iniciativa, apesar das limitações, na realidade quer manifestar a caridade pastoral e certamente mostra sua grandeza nos termos da parábola do juízo final em que o Senhor claramente coloca a acolhida dos migrantes como critério de salvação para os cristãos, por outro lado, é o mandamento do amor a exigir uma leitura crítica das posturas e ações individuais e comunitárias que a Igreja vem promovendo.

A dignidade humana e a vocação cristã colocam as pessoas e os grupos em mobilidade como atores protagonistas, não só como merecedores de apoio e assistência, quando o necessitam, mas igualmente como irmãos e irmãs de caminhada, lideranças que dinamizam e ajudam as comunidades a crescer e como testemunhas, que exercem um papel

13 TEIXEIRA, Faustino. "Histórias de fé e vida nas CEBs" em Concilium, v. 296, n. 3, 2002, pp. 38-46, aqui p. 38.

14 TEPEDINO, Ana Maria. "De Medellín a Aparecida: marcos, trajetórias, perspectivas da Igreja Latino-americana" in Atualidade Teológica n. 36, 2010, pp. 376-394. Aqui, 382. 
imprescindível na qualidade da vida cristã de inteiras comunidades. E sem as comunidades, sua acolhida e suporte, mesmo tais potencialidades podem se desgastar em vão e perderem-se, desfavorecendo a Igreja local e também os sujeitos que o Senhor agrega à comunidade pela fé migrante, porque é itinerante e também porque caminha nos passos de crentes que chegam de outras comunidades, como migrantes em fuga ou em luta por algo melhor.

\section{Referências bibliográficas}

COSENTINO Francesco. "Il nuovo volto della non credenza". Prospettive teologiche e sfide pastorali. Euntes Docdete v. 1, n. 70, 2017, pp. 11-27.

DIANICH, Severino. "Questioni di metodologia in ecclesiologia" in BARRUFFO, Antonio (ed.). Sui problemi del metodo in ecclesiologia. In dialogo con Severino Dianich. Cinisello: San Paolo, 2003.

KENAN, Milton Júnior. "Leigos e leigas no protagonismo da evangelização", s/d. Disponível em: <http://www.xaverianos.org.br/leigos-e-leigas-no-protagonismo-da-evangelizacao/>.

KLOPPENBURG Boaventura. "O protagonismo dos fiéis leigos" em Teocomunicação, v. 35, n. 148, 2005, p. 261-274.

LUSSI, Carmem. Migrações e alteridade na comunidade cristã. Ensaio de teologia da mobilidade humana. Brasília: CSEM, 2015.

LUSSI, Carmem. "A Grounded Theory da circularidade entre migrações e fé. Uma proposta metodológica para pesquisa de campo em teologia" in SOTER (Org.). Anais do Congresso da SOTER 25 . Congresso Internacional da SOTER Sociedade de Teologia e Ciências da Religião. Belo Horizonte: SOTER; 2012, pp. 1.113-1.138.

MAZZOLINI, Sandra. "Chiesa comunione e diálogo. Una correlazione essenziale" in Euntes Docete, v. 63, n. 3, 2010, pp. 149-171

RIBEIRO, Jorge Claudio. "Educar na religiosidade: pesquisa e experimento com universitários" em Revista Instrumento - Revista de Estudo e Pesquisa em Educação, v. 11, n. 2, 2009, pp. 49-58,

PORTES, Alejandro. "Convergencias teóricas e evidencias empíricas en el estudio del transnacionalismo de los inmigrantes" in Migración y desarrollo, I semestre, 2005, pp. 2-19. 
TEIXEIRA, Faustino. "Histórias de fé e vida nas CEBs" em Concilium, v. 296, n. 3, 2002, pp. 38-46.

TEPEDINO, Ana Maria. "De Medellín a Aparecida: marcos, trajetórias, perspectivas da Igreja Latino-americana" in Atualidade Teológica n. 36, 2010, pp. 376-394. 